\title{
Micro RNA-148a Targets Bcl-2 in Patients with Non-Small Cell Lung Cancer
}

\author{
Ghada Nabil Elnaggar ${ }^{1 *}$, Niveen M El-Hifnawi ${ }^{1}$, Abeer Ismail ${ }^{1}$, Maha Yahia $^{2}$, \\ Reham A A Elshimy ${ }^{1}$
}

\begin{abstract}
Objective: Lung cancer is one of the most prevalent cancers and the leading cause of cancer-related deaths worldwide. MicroRNAs regulate more than $60 \%$ of human genes, including tumor suppressor genes and oncogenes. Accordingly, they can affect cancer risk. This study aimed to evaluate the role of serum miR-148a as a non-invasive biomarker in non-small cell lung cancer (NSCLC) patients and to assess the correlation between miR-148a and Bcl-2, as one of its target proteins. Materials and Methods: A total of 50 newly diagnosed NSCLC cases and 30 apparently healthy controls were recruited in this study. MiR-148a level was measured by TaqMan- Real time RT-PCR assay and Bcl-2 level was measured by ELISA. Results: Significant lower expression of serum miR-148a and higher serum Bcl-2 levels were observed in NSCLC patients as compared to the control group ( $\mathrm{p}<0.001 \mathrm{each}$ ). A statistically significant inverse correlation was also evident between miR-148a and Bcl-2. Lower miR-148a gene expression level and higher Bcl-2 concentration were found to be associated with advanced tumor stage, lymph node involvement and distant metastasis. Conclusion: MiR-148a could be a possible biomarker for NSCLC and by targeting Bcl-2, it may offer a novel approach for treatment.
\end{abstract}

Keywords: MiR-148a- Bcl-2- NSCLC

Asian Pac J Cancer Prev, 22 (6), 1949-1955

\section{Introduction}

Lung cancer is a common malignant tumor and is considered a major cause of deaths related to cancer worldwide. (Wang et al., 2019). There are two main histological groups for lung cancer: non-small cell lung cancer (NSCLC) representing $85 \%$, and $15 \%$ small cell lung cancer (SCLC) (Siegel et al., 2015).

Early detection is important in management of NSCLC. Several protein biomarkers have been used as diagnostic tools for this disease, such as CYFRA 21-1, CEA, TPS, SCC Ag and CA-125, but due to their limited sensitivity and specificity in early detection, it is significantly urgent to develop novel non-invasive biomarkers with high accuracy, as the five-year survival rate is about $80 \%$ in early stages, but drops sharply to approximately $14 \%$ in advanced stages (stage III/IV) (Geng et al., 2014).

MicroRNAs (miRNAs) are short non-coding endogenous RNA molecules that contain approximately 22 nucleotides. They function as key regulators in various biological processes and their dysregulation results in many diseases including cancer and autoimmune disorders (Liu et al., 2018).

MicroRNA-148a is a member of MiR-148/152 family located on chromosome 7p15.2. It is expressed normally in various human tissues including cerebral, heart, liver, thymus, pancreas, renal, placenta, uterus, testis, and the hematopoietic system ( $\mathrm{Li}$ et al., 2016). It is a tumor suppressor gene and is found to be down-regulated in many types of human cancer. Evasion of apoptosis is a hallmark of cancers and is a common cause of therapeutic resistance (Sharma et al., 2019).

B cell lymphoma 2 (Bcl-2) is a critical molecule for regulating the apoptotic pathway (Youle et al., 2008). Bcl-2 signaling pathway plays important roles in human cancers. The activation of $\mathrm{Bcl}-2$ has been shown to enhance tumor growth, invasion, motility, tumor spreading, metastasis, and inhibition of apoptosis (Adams and Cory, 2007).

Several reports described the regulation of Bcl-2 by miR-148a and identified it as one of its target proteins in colorectal cancer (Zhang et al., 2011), pancreatic cancer (Zhang et al., 2014) and breast cancer (Li et al., 2017).

This study aims to evaluate the role of serum miR-148a as a non-invasive biomarker in a group of NSCLC patients. We also aimed to study the correlation between serum level of Bcl-2 protein and its regulator miR-148a, and also their association with some clinicopathological parameters. 


\section{Materials and Methods}

\section{Patients}

This study was performed on a total number of 80 participants, including 50 newly diagnosed NSCLC cases at different disease stages, and 30 age-and sex-matched apparently healthy individuals as controls. Patients were recruited from the outpatient clinics at National Cancer Institute (NCI) hospital, Cairo University, from September 2016 till September 2017. The study was permitted by the Institutional Review Board (IRB) of the NCI, Cairo University. It was permitted according to the Helsinki guidelines of studies performed on human beings and a written consent was obtained from all study subjects before enrollment in the study. All patients were subjected to; full history taking and clinical examination, ordinary biochemical and hematological investigations, imaging techniques in the form of: chest X-rays, CT scan and MRI. All patients were either cytologically or histologically confirmed NSCLC cases. Samples were obtained from all patients prior to any therapeutic or surgical intervention. Participants' age showed a mean \pm SD of $(58.1 \pm 9.1)$ years in NSCLC cases and (57.7 \pm 9.3$)$ years in the control group. Patients' characteristics are presented in table (1).

\section{Sample Collection}

Five milliliters of venous blood were withdrawn into 2 serum vacutainer tubes under complete aseptic precautions, allowed to clot for 30 minutes and centrifuged at 4000 R.P.M for 10 minutes. Yielded serum was divided into 2 micro tubes and stored at $-80^{\circ} \mathrm{C}$ till the time of analysis. First tube was used for serum quantification of miR-148a by qRT-PCR (Li et al., 2015). The second tube was used for determination of serum concentration of Bcl-2 by ELISA (Tas et al., 2005), and for determination of serum concentration of CEA by Cobas e411 Autoanalyzer, Roche.

\section{Detection of serum miR-148a by Real-Time RT-PCR}

Total RNA, including miR, was extracted using the miRNeasy Mini Kit catalog\#: 217004 (Qiagen, Germany), according to the manufacturer's instructions.

Five $\mu \mathrm{L}$ of extracted total RNA were used as a template for synthesis of cDNA performed using TaqMan ${ }^{\circledR}$ MicroRNA Reverse Transcription Kit (cat. no. 4366596) and Taqman MicroRNA Assay Primers manufactured by Thermo Scientific, USA. As recommended in the assay instructions provided, $15 \mu \mathrm{L}$ of reverse transcription reaction components were used as a total volume. Each $15-\mu 1$ reaction consists of $7 \mu 1$ master mix, $3 \mu 1$ of $5 x$ primer, and $5 \mu \mathrm{l}$ RNA sample.

The expression of $m i R-148 a$ (gene of interest) was measured by qRT-PCR using TaqMan microRNA assay kit and TaqMan ${ }^{\circledR}$ Universal PCR Master Mix II kit catalog No. 4440043 (Applied Biosystems). We pipetted $10 \mu \mathrm{l}$ of TaqMan ${ }^{\circledR}$ Universal PCR Master Mix II $(2 \times), 1 \mu 1$ of gene-specific TaqMan primer primers/ probe mix, and 6.5 $\mu \mathrm{l}$ of nuclear-free water. Then $2.5 \mu \mathrm{l}$ of each cDNA were pipetted in the corresponding well to reach a final volume of $20 \mu \mathrm{l}$ per well. The subsequent reaction conditions were as follows: $95^{\circ} \mathrm{C}$ for 10 minutes then 45 cycles at $95^{\circ} \mathrm{C}$ for 15 seconds followed by $60^{\circ} \mathrm{C}$ for 1 minute.

TaqMan qRT-PCR was performed in duplicate, and U6 snRNA was used as endogenous reference for normalizing the expression level of $m i R-148 a$ (Li et al., 2015). The relative $m i R-148 a$ gene expression level was calculated using the equation $2^{-\Delta \Delta \mathrm{CT}}$ where $\Delta \Delta \mathrm{CT}=$ (CT miR-148a - CT U6) patient sample - (CT miR-148a - CT U6) control sample (Livak and Schmittgen, 2001).

\section{Detection of serum protein Bcl-2 by ELISA technique}

Bcl-2 in serum was measured using sandwich Enzyme-linked Immunosorbent Assay Kit (catalog\#: BMS244/3) for in vitro quantitative measurement of Bcl-2 supplied by eBioscience Corp. (Thermo Fisher Scientific, USA) according to the manufacturer's instructions.

\section{Statistical Methods}

In this study, data was tested using SPSS version 25 (SPSS Inc., Chicago, IL, USA). Numerical parametric data was expressed as mean \pm standard deviation (SD) while numerical non-parametric variables were expressed as median and range. Qualitative variables were expressed as frequency and percentage. Student $\mathrm{T}$ test was used to assess the statistical significance of the difference between two study groups means. For the comparison of more than two groups' means, one-way analysis of variance (ANOVA) was used. To examine the relation between qualitative variables, Chi-square test or Fisher's exact test was used. For comparing two different groups, the Mann Whitney U nonparametric test was used, while Kruskal-Wallis nonparametric test was used for more than two independent variables. To find a correlation between two variables Spearman's rho (r) was calculated. The Receiver Operating Characteristic (ROC) curve was used to determine the cut-off values and to analyze the diagnostic utility of different markers. A p-value of less than 0.05 was considered statistically significant. All p-values are two sided.

\section{Results}

Down-regulation of serum miR-148a in NSCLC serum samples

MiR-148a was significantly down-regulated while Bcl-2 and CEA were up-regulated in the serum of NSCLC patients as shown in Figure 1 and Table 2.

\section{Receiver Operating Characteristic (ROC) Curve}

The diagnostic value of miR-148a and Bcl-2 were evaluated by ROC analysis. The results shown in Figure (2), suggested that NSCLC patients could be distinguished from apparently healthy controls according to $m i R-148 a$ expression at a cut-off value 3 . The area under the curve (AUC) was 0.970 (95\% CI 0.935-1, p<0.001), sensitivity was $90 \%$, specificity was $93.3 \%$, positive predictive value (PPV) was $95.7 \%$, negative predictive value (NPV) was $84.8 \%$ and total accuracy was $91.2 \%$. For Bcl-2, at a cut-off value $1.7 \mathrm{ng} / \mathrm{ml}$, AUC was $0.829(95 \% \mathrm{CI}$ $0.718-0.941, \mathrm{p}<0.001)$, sensitivity was $90 \%$, specificity was $76.7 \%$, PPV was $86.6 \%$, NPV was $82.1 \%$ and total accuracy was $85 \%$. 
Table 1. Association between Study Markers with Different Clinicopathological Characteristics in NSCLC Patients

\begin{tabular}{|c|c|c|c|c|c|c|c|}
\hline & Variable & $n$ & $\%$ & $\begin{array}{l}\text { Serum miR-148a } \\
\text { median (range) }\end{array}$ & P value & $\begin{array}{c}\text { Serum Bcl-2 } \\
\text { median (range) }\end{array}$ & $P$ value \\
\hline \multirow[t]{2}{*}{ Gender } & Male & 44 & 88 & $0.5(0.01-5.6)$ & 0.56 & $2.5(0.8-5.5)$ & 0.87 \\
\hline & Female & 6 & 12 & $0.7(0.02-4.3)$ & & $2.4(2.0-3.8)$ & \\
\hline \multirow[t]{2}{*}{ Smoking Status } & Yes & 44 & 88 & $0.5(0.01-5.6)$ & 0.56 & $2.5(0.8-5.5)$ & 0.87 \\
\hline & No & 6 & 12 & $0.7(0.02-4.3)$ & & $2.4(2.0-3.8)$ & \\
\hline \multirow[t]{3}{*}{ Pathological Subtypes } & Adenocarcinoma & 26 & 52 & $0.4(0.01-4.3)$ & 0.095 & $2.8(1.5-5.5)$ & 0.085 \\
\hline & $\mathrm{SCC}$ & 16 & 32 & $1.1(0.01-5.6)$ & & $2.2(0.8-4.6)$ & \\
\hline & Large Undifferentiated & 8 & 16 & $0.3(0.01-2.2)$ & & $2.6(2.2-5.1)$ & \\
\hline \multirow[t]{3}{*}{ Grade } & I & 3 & 6 & $2.8(0.33-4.3)$ & 0.353 & $2.1(2.1-3.8)$ & 0.725 \\
\hline & II & 25 & 50 & $0.5(0.01-5.6)$ & & $2.5(0.8-5.5)$ & \\
\hline & III & 22 & 44 & $0.5(0.01-5.1)$ & & $2.5(1.2-5.1)$ & \\
\hline \multirow[t]{3}{*}{ Differentiation } & Well & 3 & 6 & $2.8(0.33-4.3)$ & 0.358 & $2.1(2.1-3.8)$ & 0.725 \\
\hline & Moderate & 24 & 48 & $0.4(0.01-5.6)$ & & $2.5(0.8-5.5)$ & \\
\hline & Poor & 23 & 46 & $0.6(0.01-5.1)$ & & $2.5(1.2-5.1)$ & \\
\hline \multirow[t]{6}{*}{ Stage } & I & 12 & 24 & $2.9(0.82-5.6)$ & $<0.001 *$ & $2.0(0.8-2.1)$ & $<0.001^{*}$ \\
\hline & II & 6 & 12 & $2.0(0.74-2.3)$ & & $1.7(1.5-2.3)$ & \\
\hline & III & 25 & 50 & $0.3(0.01-2.2)$ & & $2.7(2.3-3.8)$ & \\
\hline & IV & 7 & 14 & $0.1(0.01-0.2)$ & & $4.3(4.0-5.5$ & \\
\hline & Early stage (I + II) & 18 & 36 & $2.3(0.7-5.6)$ & $<0.001 *$ & $1.9(0.8-5.5)$ & $<0.001^{*}$ \\
\hline & Late stage (III + IV) & 32 & 64 & $0.2(0.01-2.2)$ & & $3.2(2.3-5.5)$ & \\
\hline \multirow[t]{2}{*}{ Lymph Node Metastasis } & Present & 34 & 68 & $1.7(0.05-5.6)$ & $<0.001^{*}$ & $2.1(0.8-3.8)$ & $0.002 *$ \\
\hline & Absent & 16 & 32 & $0.3(0.01-2.3)$ & & $2.6(1.5-5.5)$ & \\
\hline \multirow[t]{2}{*}{ Distant Metastasis } & Present & 6 & 12 & $0.7(0.01-5.6)$ & $0.002 *$ & $2.4(0.8-4.3)$ & $<0.001 *$ \\
\hline & Absent & 44 & 88 & $0.1(0.01-0.2)$ & & $4.4(4.0-5.5)$ & \\
\hline
\end{tabular}

Qualitative data are represented as frequency (percentage); ${ }^{\mathrm{P}}$ value $<0.05$ is significant; SCC, Squamous cell carcinoma.

Correlations of miR-148a and Bcl-2 in the studied groups

Using Spearman's correlation coefficient showed that significant negative correlation was found between miR-148a and Bcl-2, also there was a significant negative correlation between miR-148a with CEA, tumor size and stage. Bcl-2 showed a significant positive correlation with CEA, tumor size and stage as shown in Table 3.

Relation between Serum miR-148a Level, Bcl-2 Level and Clinicopathological Characteristics of NSCLC Group

The relative expression of serum $m i R-148 a$ and $B c l-2$ of the NSCLC patients were studied in relation to their clinicopathological data. MiR-148a was significantly lower in sera of patients with late stage (III and IV) than in those with early-stage NSCLC $(p<0.001)$. Also, miR-148a had a statistically significant association with lymph node involvement $(\mathrm{p}<0.001)$ and with distant metastasis $(p=0.002)$. Bcl-2 had a statistically significant association with stages $(\mathrm{p}<0.001)$, lymph

Table 2. Level of miR-148a, Bcl-2 and CEA in NSCLC Patients and Control Group

\begin{tabular}{lccc}
\hline Variable & $\begin{array}{c}\text { NSCLC group } \\
(\mathrm{n}=50)\end{array}$ & $\begin{array}{c}\text { Control group } \\
(\mathrm{n}=30)\end{array}$ & P value \\
\hline Serum miR-148a & $0.5(0.01-5.6)$ & $3.2(0.004-8.7)$ & $<0.001^{*}$ \\
Serum Bcl-2 & $2.5(0.8-5.5)$ & $0.9(0.7-1.7)$ & $<0.001^{*}$ \\
Serum CEA & $7.7(1.1-96.4)$ & $2.7(0.25-6)$ & $<0.001^{*}$ \\
\hline
\end{tabular}

$* \mathrm{P}$ value $<0.05$ is significant; Data shown as median (range). node involvement $(\mathrm{p}=0.002)$ and distant metastasis $(p<0.001)$. No significant differences were found with gender, smoking status, pathological subtypes, grade or differentiation as shown in Table 1.

\section{Discussion}

Recently, the emergence of small non coding RNAs called microRNAs, that play important role in oncogenesis, has opened novel opportunities for early cancer diagnosis. MiRNAs have been found to regulate different cellular processes, such as proliferation, differentiation, cell cycle and apoptosis (Bartel, 2018). They have been associated

Table 3. Correlations of miR-148a and Bcl-2 with Other Studied Parameters in NSCLC Cases

\begin{tabular}{lcccc}
\hline & \multicolumn{2}{c}{ miR-148a } & \multicolumn{2}{c}{ Bcl-2 } \\
& $R$ & $P$ & $R$ & $P$ \\
\hline Age & -0.19 & 0.141 & 0.251 & 0.079 \\
CEA & -0.279 & $0.049 *$ & 0.361 & $0.010^{*}$ \\
Grade & -0.119 & 0.41 & 0.112 & 0.44 \\
Differentiation & -0.083 & 0.568 & 0.094 & 0.518 \\
Size & -0.456 & $0.001 *$ & 0.376 & $0.007 *$ \\
Stage & -0.823 & $<0.001 *$ & 0.895 & $<0.001 *$ \\
Bcl-2 & -0.799 & $<0.001 *$ & - & - \\
\hline *P value $<0.05$ is significant. & & & \\
\hline
\end{tabular}


A

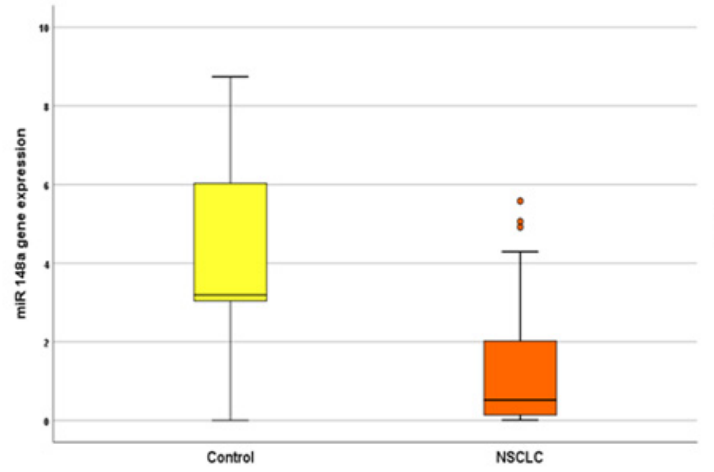

B

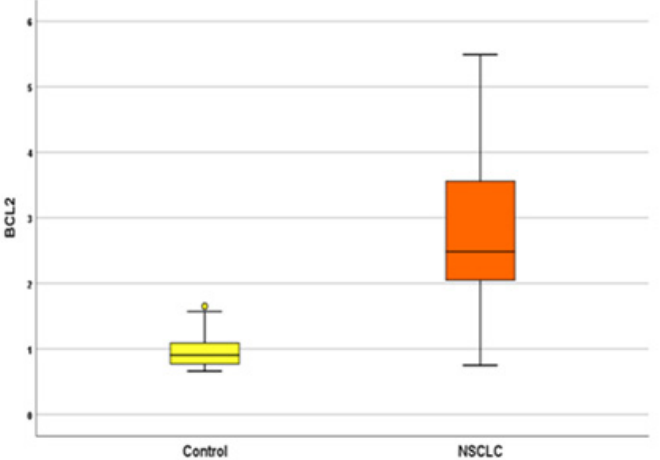

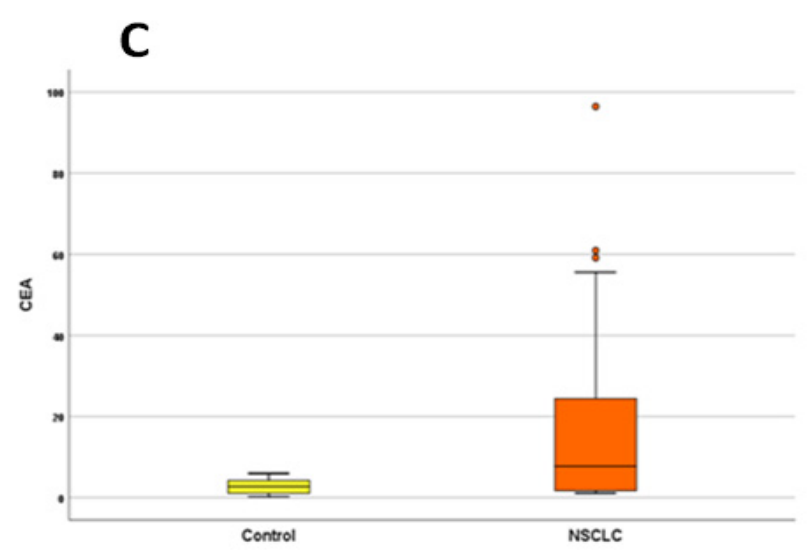

Figure 1. Box Plots for miR-148a, Bcl-2 and CEA Concentrations in NSCLC Cases versus Control. MiR-148a gene expression level is significantly lower in NSCLC group (A) compared to control group $(\mathrm{p}<0.001)$. Significantly higher Bcl-2 concentration (B) and CEA level (C) in NSCLC cases compared to control group ( $\mathrm{p}<0.001$ each).

with tumorigenesis by functioning as tumor suppressors or oncogenes (Debnath et al., 2017). There is a strong need to elucidate new mechanisms of NSCLC development, so as to establish an accurate and cost-effective screening method for this cancer.

In this study, we evaluated the expression of serum $m i R-148 a$ in 50 NSCLC patients and 30 controls. $M i R-148 a$ altered expression can be detected in various types of cancers and has been linked to the clinical classification and prognosis of tumors (Li et al., 2016).

Our data showed that miR-148a was significantly down-regulated in serum of NSCLC patients when compared to control group. This was in agreement with the studies of Li et al., (2015); Yang et al., (2015), Huang, (2016) and Kumar et al., (2020), proving that miR-148a is considered a tumor suppressor gene in lung cancer.

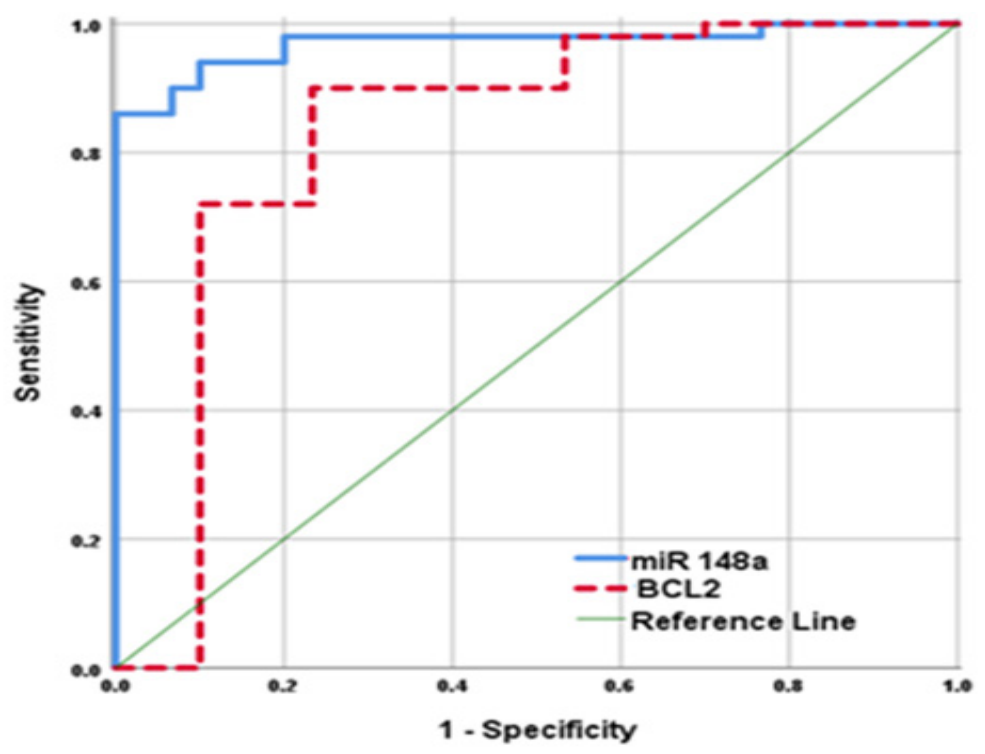

Figure 2. ROC of Serum miR-148a Gene Expression and Bcl-2 Concentration for Prediction of NSCLC Occurrence. 
This result was also supported by several studies on tissue samples. Li et al., (2013), He and Xue (2017), Chen et al., (2017) and Bai et al., (2019) all reported that $m i R$ $148 a$ expression was decreased in NSCLC tissues and cell lines compared with that in the corresponding adjacent normal lung tissues.

Similarly, the downregulated expression of $m i R-148 a$ was reported in various types of cancers including gastric (Chen et al., 2013a; Zheng et al., 2014), colorectal (Takahashi et al., 2012), pancreatic (Li et al., 2016), liver (Heo et al., 2014), esophageal (Wijnhoven et al., 2010), breast (Li et al., 2017) and urogenital system cancers (Fujita et al., 2010; Zhou et al., 2012; Lombard et al., 2015).

MiR-148a regulates cell survival mechanisms by acting on different target genes to affect their function. As a tumor suppressor gene, it inhibits cell proliferation and induces apoptosis by suppressing the action of multiple proteins as Bcl-2 (Zheng et al., 2011; Wang, 2020), ROCK1 (Li et al., 2013), CCKBR (Zhang et al., 2014 a), and DNMT1 (Lombard et al., 2015). Thus, its down regulation is strongly associated with carcinogenesis.

In order to further investigate how miR-148a functions in lung cancer pathogenesis, $\mathrm{Bcl}-2$ was studied as one of its molecular targets. We found that serum Bcl-2 concentration in NSCLC patients was significantly higher compared to the control group. This was in agreement with a study done by Tas et al., (2005) which supports that Bcl-2 is an important anti-apoptotic molecule, well accepted for NSCLC development (Huang et al., 2015).

Similarly, high Bcl-2 levels have been detected in a variety of tumor types, including small cell lung, melanoma, breast, prostate, colorectal, and bladder cancers, and especially in human lymphoid malignancies (Dai et al., 2016).

The results of the current study in serum samples are in keeping with data from the literature (Nalluri et al., 2015; D’Aguanno and Del Bufalo, 2020). These results suggest that decreased apoptosis associated with serum Bcl-2 elevation occur in lung cancer patients.

Regarding association between miR-148a with the clinicopathologic parameters examined in patients, our results revealed significant association between its low expression level with advanced tumor stage, lymph node involvement and distant metastasis. Also, miR-148a showed a significant negative correlation with CEA and tumor size. This can be referred to its role in the initiation and progression of NSCLC by acting on different target genes that inhibit cell migration and invasion as SMAD2 (Wang et al., 2013), DNMT1 (Lombard et al., 2015), MMP7 (Sakamoto et al., 2014), MET (Zhang et al., 2014b), and WNT1 (Yan et al., 2014).

As for Bcl-2, there was also a significant association between its high level with advanced tumor stage, lymph node involvement and distant metastasis. A significant positive correlation was found between its level with CEA and tumor size. In addition, no significant correlation was found between either miR-148a or Bcl-2 with other clinicopathologic parameters including age, gender, smoking status, histological type, grade, or differentiation.

Others studies differ in what they demonstrated regarding the association between miR-148a or Bcl-2 with clinicopathological parameters in NSCLC patients. Huang (2016) compared the expression level of $m i R-148 a$ between early-stage (stage I) and late-stage (stage II-III) NSCLC groups, and similar to our results, he found that the expression levels change significantly in correlation with the development of lung cancer. In concordance with results of the current study, Li et al., (2015) reported that low $m i R-148 a$ expression was significantly correlated with presence of lymphatic metastasis. And similarly, no correlation was observed with other clinicopathologic factors, including age, gender, tumor differentiation, and histology. Also, Yang et al., (2015) reported significant association between miR-148a expression with tumor size and lymph node metastasis. Chen et al., (2013b) similarly reported that patients with lymph node metastasis and advanced clinical stage had a significantly lower expression of miRNA $148 a$.

Up to our knowledge, this is the first study that correlates serum Bcl-2 measured by ELISA with serum miR-148a in NSCLC. It revealed a significant inverse correlation between miR-148a and Bcl-2 in NSCLC and healthy groups with $\mathrm{P}$-value $<0.001$ and correlation coefficient $(\mathrm{r})=(-0.799)$.

Several studies described the regulation of Bcl-2 by miR-148a and identified it as one of its target proteins. This was reported in breast cancer by Li et al., (2017) who found that restoring expression of $m i R-148 a$ suppressed the expression of $\mathrm{Bcl}-2$ at the level of both mRNA and protein, and also upregulation of miR-148a caused a subsequent reduction of proliferation and an increase in apoptosis, confirming their involvement in the oncogenesis of breast cancer.

Zhang et al., (2014a) similarly found that miR-148a regulates the growth and apoptosis in pancreatic cancer by targeting $\mathrm{Bcl}-2$, and that the 3 '-UTR of $\mathrm{Bcl}-2$ is a functional target site for miR-148a silencing of Bcl-2.

Another study in colorectal cancer by Zhang et al., (2011) proved that miR-148a promotes apoptosis by targeting Bcl-2. And in agreement with our findings, a strong inverse correlation between them was observed ( $\mathrm{P}$-value $<0.001$ and correlation coefficient $(\mathrm{r})=(-0.604)$.

The diagnostic value of miR-148a was evaluated by ROC analysis. AUC: 0.970 (95\% CI: 0.935-1) at Cut-off: 3, Sensitivity: 90\%, Specificity: 93.3\%. In agreement with our results, Li et al., (2015) reported that serum $m i R-148 a$ gene expression level was significantly lower in NSCLC patients than that of healthy individuals. His study showed sensitivity of $77.8 \%$ and specificity of $80 \%$ at a cut-off level of 3.33. AUC was 0.775 (95\% CI: $0.628-0.885$ ). Yang et al., (2015) also reported AUC: 0.90 (95\% CI: $0.86-0.95$ ) with sensitivity of $85 \%$ and specificity of $83 \%$.

Several studies were done to identify Bcl-2 inhibitors to be used for cancer therapy. Starting from the clinical use of antisense oligonucleotides directed against Bcl-2, and passing through $\mathrm{BH} 3$ mimetics that showed severe on-target toxicity, recent FDA approval of the $\mathrm{BH} 3$ mimetic Venetoclax validated the clinical relevance of using Bcl-2 anti-apoptotic members as therapeutic targets, not only for hematologic malignancies but also for breast carcinoma (D'Aguanno and Del Bufalo, 2020). We hope 
positive results can offer a way for these therapeutic strategies to be used for treatment of a large amount of solid malignancies including NSCLC.

In conclusion, miR-148a was down-regulated in NSCLC when compared to healthy controls which suggests that miR-148a may be used as a potential biomarker in NSCLC. Also, its expression was negatively correlated with serum $\mathrm{Bcl}$-2, which was up-regulated in NSCLC patients, and this may explain the influence of miR-148a on increased risk of NSCLC and may offer a novel approach for treatment. Low miR-148a gene expression level was associated with advanced tumor stage, lymph node involvement and distant metastasis. So, it could be a prognostic factor in NSCLC.

\section{Author Contribution Statement}

Niveen M El-Hifnawi, Abeer Ismail and Reham A.A. Elshimy planed and designed the research; Ghada Nabil Elnaggar participated in conception, interpretation of laboratory data and practical work. Maha Yahia and Ghada Nabil Elnaggar collecting clinical data and statistical analysis. All authors - contributing to the study design, participated in writing and editing the final version of the manuscript, read and approved the final manuscript.

\section{Acknowledgements}

The authors would like to thank the chemists and technicians of the Clinical Chemistry and Tumor Marker laboratory at National Cancer Institute (NCI), Cairo University.

\section{Funding Statement}

This work was funded by National Cancer Institute (NCI), Cairo University and was a part of Ghada Nabil Elnaggar approved MD thesis.

\section{Ethical Approval and Consent}

The study was approved by the Institutional Review Board (IRB) of the National Cancer Institute (NCI), Cairo University. A written consent was obtained from all subjects before enrollment in the study.

\section{Conflict of Interest}

The authors declare no conflict of interest.

\section{References}

Adams JM, Cory S (2007). The Bcl-2 apoptotic switch in cancer development and therapy. Oncogene, 26,1324-37.

Bai Y, Lang L, Zhao W, Niu R (2019). Long non-coding RNA HOXA11-AS promotes non-small cell lung cancer tumorigenesis through microRNA-148a-3p/DNMT1 regulatory axis. Onco Targets Ther, 12, 11195-206.

Bartel DP (2018). Metazoan microRNAs. Cell, 173, 20-51.

Chen Z, Saad R, Jia P, et al (2013a). Gastric adenocarcinoma has a unique microRNA signature not present in esophageal adenocarcinoma. Cancer, 119, 1985-93.

Chen Y, Min L, Zhang X, et al (2013b). Decreased miRNA-148a is associated with lymph node metastasis and poor clinical outcomes and functions as a suppressor of tumor metastasis in non-small cell lung cancer. Oncol Rep, 30, 1832-40.
Chen Y, Min L, Ren C, et al (2017). MiRNA-148a serves as a prognostic factor and suppresses migration and invasion through Wnt1 in non-small cell lung cancer. PLoS One, 12, e0171751.

D’Aguanno S, Del Bufalo D (2020). Inhibition of Anti-Apoptotic Bcl-2 Proteins in Preclinical and Clinical Studies: Current Overview in Cancer. Cells, 9, 1287.

Dai H, Meng XW, Kaufmann SH (2016). BCL2 Family, Mitochondrial Apoptosis, and Beyond. Cancer Transl Med, 2, 7-20.

Debnath T, Deb Nath NC, Kim EK, Lee KG (2017). Role of phytochemicals in the modulation of miRNA expression in cancer. Food Funct, 8, 3432-42.

Fujita Y, Kojima K, Ohhashi R, et al (2010). MiR-148a attenuates paclitaxel resistance of hormone-refractory, drug-resistant prostate cancer PC3 cells by regulating MSK1 expression. J Biol Chem, 285, 19076-84.

Geng Q, Fan T, Zhang B, et al (2014). Five microRNAs in plasma as novel biomarkers for screening of early-stage non-small cell lung cancer. Respir Res, 15, 149.

He M, Xue Y (2017). MicroRNA-148a suppresses proliferation and invasion potential of non-small cell lung carcinomas via regulation of STAT3. Onco Targets Ther, 10, 1353-61.

Heo MJ, Kim YM, Koo JH, et al (2014). MicroRNA-148a dysregulation discriminates poor prognosis of hepatocellular carcinoma in association with USP4 overexpression. Oncotarget, 5, 2792-806.

Huang P, Ye B, Yang Y, Shi J, Zhao H (2015). MicroRNA-181 functions as a tumor suppressor in non-small cell lung cancer (NSCLC) by targeting Bcl-2. Tumour Biol, 36, 3381-7.

Huang MX (2016). Down-expression of circulating micro ribonucleic acid (miRNA)-148/152 family in plasma samples of non-small cell lung cancer patients. $J$ Cancer Res Ther, 12, 671-675.

Kumar S, Sharawat SK, Ali A, et al (2020). Identification of differentially expressed circulating serum microRNA for the diagnosis and prognosis of Indian non-small cell lung cancer patients. Curr Probl Cancer, 44, 100540.

Li J, Song Y, Wang Y, Luo J, Yu W (2013). MicroRNA-148a suppresses epithelial-to-mesenchymal transition by targeting ROCK1 in non-small cell lung cancer cells. Mol Cell Biochem, 380, 277-82.

Li L, Chen YY, Li SQ, Huang C, Qin YZ (2015). Expression of miR-148/152 family as potential biomarkers in non-smallcell lung cancer. Med Sci Monit, 21, 1155-61.

Li Y, Deng X, Zeng X, Peng X (2016). The Role of Mir-148a in Cancer. $J$ Cancer, 7, 1233-41.

Li Q, Ren P, Shi P, et al (2017). MicroRNA-148a promotes apoptosis and suppresses growth of breast cancer cells by targeting B-cell lymphoma 2. Anticancer Drugs, 28, 588-95.

Liu H, Lei C, He Q, et al (2018). Nuclear functions of mammalian MicroRNAs in gene regulation, immunity and cancer. $\mathrm{Mol}$ Cancer, 17, 64.

Livak KJ, Schmittgen TD (2001). Analysis of relative gene expression data using real-time quantitative PCR and the $2^{-\Delta \Delta \mathrm{CT}}$ method. Methods, 25, 402-8.

Lombard AP, Mooso BA, Libertini SJ, et al (2015). MiR-148a dependent apoptosis of bladder cancer cells is mediated in part by the epigenetic modifier DNMT1. Mol Carcinog, $\mathbf{5 5}, 757-67$.

Nalluri S, Ghoshal-Gupta S, Kutiyanawalla A, et al (2015). TIMP-1 inhibits apoptosis in lung adenocarcinoma cells via interaction with $\mathrm{Bcl}-2$. PLoS One, 10, $\mathrm{e} 0137673$.

Sakamoto N, Naito Y, Oue N, et al (2014). MicroRNA-148a is downregulated in gastric cancer, targets MMP7, and indicates tumor invasiveness and poor prognosis. Cancer Sci, 105, 236-43. 
Sharma A, Boise LH, Shanmugam M (2019). Cancer metabolism and the evasion of apoptotic cell death. Cancers (Basel), 11, 1144.

Siegel RL, Miller KD, Jemal A (2015). Cancer statistics, 2015. CA Cancer J Clin, 65, 5-29.

Takahashi M, Cuatrecasas M, Balaguer F, et al (2012). The clinical significance of MiR-148a as a predictive biomarker in patients with advanced colorectal cancer. PLoS One, 7, e46684.

Tas F, Duranyildiz D, Oguz H, et al (2005). The value of serum Bcl-2 levels in advanced lung cancer patients. Med Oncol, 22, 139-43.

Wang H (2020). MicroRNAs and apoptosis in colorectal cancer. Int J Mol Sci, 21, 5353.

Wang K, Chen R, Feng Z, et al (2019). Identification of differentially expressed genes in non-small cell lung cancer. Aging (Albany NY), 11, 11170-85.

Wang SH, Li X, Zhou LS, et al (2013). MicroRNA-148a suppresses human gastric cancer cell metastasis by reversing epithelial-to-mesenchymal transition. Tumour Biol, 34, 3705-12.

Wijnhoven BP, Hussey DJ, Watson DI, et al (2010). MicroRNA profiling of Barrett's oesophagus and oesophageal adenocarcinoma. Br J Surg, 97, 853-61.

Yan H, Dong X, Zhong X, et al (2014). Inhibitions of epithelial to mesenchymal transition and cancer stem cells-like properties are involved in miR-148a-mediated anti-metastasis of hepatocellular carcinoma. Mol Carcinog, 53, 960-9.

Yang JS, Li BJ, Lu HW, et al (2015). Serum miR-152, miR-148a, miR-148b, and miR-21 as novel biomarkers in non-small cell lung cancer screening. Tumour Biol, 36, 3035-42.

Youle RJ, Strasser A(2008). The BCL-2 protein family: opposing activities that mediate cell death. Nat Rev Mol Cell Biol, 9, 47-59.

Zhang H, Li Y, Huang Q, et al (2011). MiR-148a promotes apoptosis by targeting Bcl-2 in colorectal cancer. Cell Death Differ, 18, 1702-10.

Zhang R, Li M, Zang W, et al (2014a). MiR-148a regulates the growth and apoptosis in pancreatic cancer by targeting CCKBR and Bcl-2. Tumour Biol, 35, 837-44.

Zhang JP, Zeng C, Xu L, et al (2014b). MicroRNA-148a suppresses the epithelial-mesenchymal transition and metastasis of hepatoma cells by targeting Met/Snail signaling. Oncogene, 33, 4069-76.

Zheng B, Liang L, Wang C, et al (2011). MicroRNA148a suppresses tumor cell invasion and metastasis by downregulating ROCK1 in gastric cancer. Clin Cancer Res, 17, 7574-83.

Zheng G, Xiong Y, Xu W, et al (2014). A two-microRNA signature as a potential biomarker for early gastric cancer. Oncol Lett, 7, 679-84.

Zhou X, Zhao F, Wang ZN, et al (2012). Altered expression of miR-152 and miR-148a in ovarian cancer is related to cell proliferation. Oncol Rep, 27, 447-54.

\section{๑ळब}

This work is licensed under a Creative Commons AttributionNon Commercial 4.0 International License. 